\title{
Learning of a postural control task by elderly post-stroke patients
}

\author{
Aprendizagem de uma tarefa de controlo postural em indivíduos pós- \\ Acidente Vascular Cerebral
}

\author{
Giordano Marcio Gatinho Bonuzzi $\mathbf{i}^{1,2^{*}}$, Tatiana Beline Freitas ${ }^{1}$, Umberto Cesar Corrêa ${ }^{1}$, \\ Andrea Michele Freudenheim ${ }^{1}$, José Eduardo Pompeu ${ }^{3}$, Camila Torriani-Pasin ${ }^{1}$ \\ ORIGINAL ARTICLE | ARTIGO ORIGINAL
}

\begin{abstract}
The aim of this study was to compare the learning process of a postural control task between post-stroke patients and healthy subjects. The sample was composed of 20 post-stroke individuals (Experimental Group) and 20 aged matched healthy individuals (Control Group). Participants practiced a postural control task in a virtual environment with increasing of complexity. The study design involved four phases: pretest (five trials), acquisition phase (four blocks of thirty minutes), post-test (five trials), and retention test (five trials after a week without practice). The statistical analysis was run by a $2 \times 3$ ANOVA (groups $\mathrm{x}$ learning tests). Results: There was no difference in motor learning between Experimental Group and Control Group $(\mathrm{F}=41.22 ; \mathrm{p}=0.88)$. In addition, it was founded that the Control Group could learn the task in a higher-level complexity than Experimental Group $(\mathrm{F}=4.77 ; \mathrm{p}=0.01)$, and both groups increased the error during the trials of practice $(\mathrm{F}=0.53 ; \mathrm{p}=0.00)$ because of task complexity. Conclusion: Therefore has been found that post-stroke individuals have the ability to learn a postural control task similar to healthy subjects, and the task complexity seems to be a key-factor in order to differentiate stroke from healthy subject's motor learning process.
\end{abstract}

Key Words: Stroke, Postural Control, Motor learning.

RESUMO

O objetivo deste estudo foi comparar o processo de aprendizagem de uma tarefa de controle postural entre indivíduos pós-Acidente Vascular Cerebral (AVC) e indivíduos saudáveis. Participaram do estudo 20 indivíduos pós- AVC (Grupo Experimental) e 20 indivíduos saudáveis pareados por idade (Grupo Controle). Os participantes praticaram uma tarefa de controle postural em ambiente virtual com incremento de complexidade. O delineamento foi constituído de quatro fases: pré-teste (cinco tentativas), fase de aquisição (quatro blocos de trinta minutos), pós-teste (cinco tentativas) e teste de retenção (cinco tentativas após uma semana sem prática). Para a análise estatística foi realizada uma ANOVA 2 × 3 (grupos $\mathrm{x}$ testes de aprendizagem). Resultados: Não houve diferença na aprendizagem motora entre os grupos ( $\mathrm{F}=$ 41.22; $\mathrm{p}=0.88$ ), o Grupo Controle conseguiu desempenhar a tarefa em níveis mais altos de complexidade que o Grupo Experimental $(\mathrm{F}=4.77 ; \mathrm{p}=0.01)$, e ambos os grupos incrementaram o número de erros ao longo dos blocos de prática $(\mathrm{F}=0.53 ; \mathrm{p}=0.00)$ por causa do aumento de complexidade. Conclusão: Podese verificar que indivíduos pós-AVC possuem a mesma capacidade de aprender uma tarefa de controle postural que indivíduos saudáveis, e que a complexidade aparenta ser um aspecto crucial para diferenciar o processo de aprendizagem motora destas diferentes populações.

Palavras-chave: Acidente Vascular Cerebral, Controle Postural, Aprendizagem Motora.

\footnotetext{
Manuscript received at June $7^{\text {th }} 2015$; Accepted at April $17^{\text {th }} 2016$

${ }^{1}$ Laboratório de Comportamento Motor, Escola de Educação Física e Esporte, Universidade de São Paulo, USP, São Paulo, Brasil

${ }^{2}$ Universidade Paulista, São Paulo, Brasil

${ }^{3}$ Departamento de Neurociência e Comportamento, Instituto de Psicologia, Escola de Medicina, Universidade de São Paulo, USP, São Paulo, Brasil

* Corresponding author. Avenida Professor Mello Moras, 65 - Cidade Universitária - São Paulo, SP, Brasil. E-mail: giordanomgb@gmail.com
} 


\section{INTRODUCTION}

In the last few years the stroke has been acknowledge as the main cause of dead and incapacity in the world (Roger et al., 2012). Stroke refers to a cutting off of the blood flow in specific areas in the brain. This blood deprivation implies significant modifications in the somatossensorial, cognitive, and motor systems, which results in limitation in performance of a numerous motor skills, including those of postural control (Langhorne, Bernhardt, \& Kwakkel, 2011).

Postural control involves the spatio-temporal control of the body in two dimensions: (1) postural orientation - related to the ability of maintaining the appropriated relation between body segments, and between them and the environment; (2) postural stability or balance center of mass (CM) control in relation the base of support (BS) (Horak \& Macpherson, 1996).

The poor postural control of post-stroke individuals has shown a multifactorial etiology, such as biomechanical restrictions, deficits in sensorial detection, integration and perception, inappropriate balance reorganization strategies, poor cognitive processing, and erroneous perception of verticality (Oliveira, Medeiros, Frota, Greters, \& Conforto, 2008). This conjunct of factors negatively affects the quality of life to the extent that it affects the performance of activities of daily living (ADL), increasing of the incidence of falls, and hence restricts the sociocultural participation (Batchelor, Mackintosh, Said, \& Hill, 2012; Langhorne et al., 2011; Oliveira et al., 2008). In this sense, the analysis of the learning or relearning process of postural control has been identified as an important aspect to be investigated (Kitago \& Krakauer, 2013; Krakauer, 2006).

Although there are assumptions on the mechanisms related to motor learning to also be affected by the stroke, such as intrinsic feedback, working and long-term memory, decisionmaking, motor planning and, certainly, the effector mechanisms for perform tasks (Kitago \& Krakauer, 2013; Krakauer, 2006), the literature still has not provide strong support to this. For instance, while some experiments reported similar learning between post-stroke and healthy individuals (Boyd \& Winstein, 2004; Platz, Denzler, Kaden, \& Mauritz, 1994; Pohl, Mcdowd, Filion, Richards, \& Stiers, 2006; Vidoni \& Boyd, 2009; Winstein, Merians, \& Sullivan, 1999), others showed worse learning of post-stroke individuals in comparison to those healthy ones (Boyd, Vidoni, \& Wessel, 2010; Iofee, Chernikova, Umarova, Katsuba, \& Kulikov, 2010; Pohl \& Winstein, 1999; Ustinova, Chernikova, Iofee, \& Silva, 2001). Furthermore, the most of the studies have investigated the motor learning of reaching and grasping or tracking tasks. Therefore, postural control tasks need further investigation. Importantly, in the few studies with postural control task (Iofee et al., 2010; Ustinova et al., 2001) failed in accessing the motor learning phenomenon by did not consider retention and/or transfer tests in their design. As is well known these tests are necessary for separating transient from permanent effects of learning (Magill, 2000; Schmidt \& Lee, 2011; Schmidt \& Wrisberg, 2008).

Therefore, this study aimed to investigate the learning of a postural control task in post-stroke and healthy individuals. Our hypothesis was that individuals post-stroke improve performance in function of practice, as reported in previous studies (Iofee et al., 2010; Ustinova et al., 2001), however, the perceptual and motor deficits of post-stroke individuals do not allow persistence in the retention test, in other words, there was no motor learning.

\section{METHODS}

\section{Participants}

Twenty post-stroke and 20 healthy individual with average age of 64.8 ( \pm 9.2 years) were assigned to the experimental (EG) and control groups (CG).

For post-stroke individuals the inclusion criteria were: single ischemic event of the anterior circulation, confirmed by the neurologist or neuroimaging, injury time of at least 6 months, mild or moderate dysfunction according to Orpington Prognostic Scale (ORPINGTON) (Lai, Duncan, \& Keighley, 1998), $\geq 23$ points in the Mini Mental State Examination (MMSE) (Bertolucci, Brucki, Campacci, \& Juliano, 1994). 
Exclusion criteria were: not preserved visual and auditory acuity, not keep standing position without assistive devices for at least 2 minutes; depression detected by the Depression Questionnaire Beck II (BECK) (Beck, 1967), severe proprioceptive deficits in sensory section of the Fugl-Meyer Scale (FMS) (Fugl-Meyer, Jääskö, Leyman, Olsson, \& Steglind, 1975), severe aphasia, spacial heminegligence detected by the star cancellation test (Wilson, Cockburn, \& Halligan, 1987), absence of 2 or more times in predetermined days for the experimental study procedures, experience in video games involving virtual reality.

To characterize the sample and ensure the homogeneity of covariates, the following assessment instruments were used: Orpington Scale, MMSE, FMS, as well as the Berg Balance Scale (BERG) (Berg, 1993) and the Functional Reach Test (FRT) (Duncan, Weiner, Chandler, \& Studenski, 1990). In addition, we also collected additional information such as lesion topography (hemispheric location), age, gender and time of injury.

The protocol used in the study followed the guidelines for Responsible Conduct of Research of the American Psychological Association and was approved by an institutional review board for the protection of human subjects at the University of São Paulo (624,520). All study participants received detailed explanations about the research and signed the consent term.

\section{Instruments}

The Nintendo Wii video game system provided of the balance board was used to perform the task. This system consists of a motion sensor, which allows the representation of the player's center of pressure displacement in the virtual environment.

A white wall free of imperfections was used to project the task in front of the participants. The projection size was $1.5 \mathrm{~m}$ long by $2.2 \mathrm{~m}$ wide and $1.6 \mathrm{~m}$ high. The participant was positioned at a distance of 2.5 meters from the projection. These standardizations are shown in Figure 1.

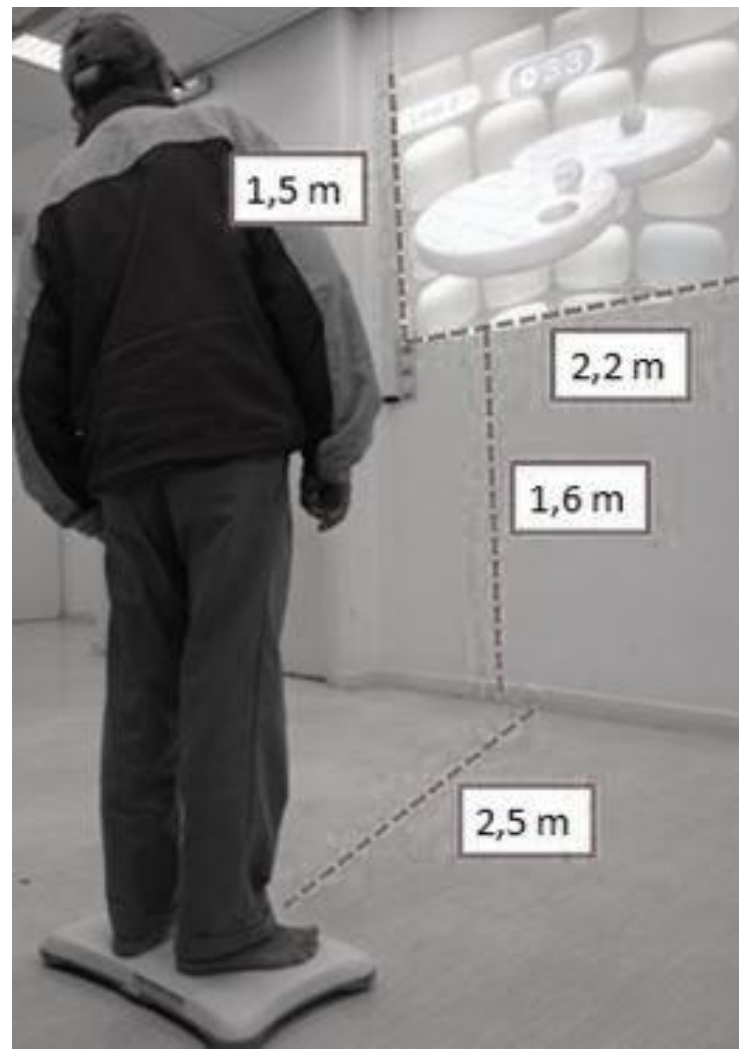

Figure 1. Nintendo Wii video game with balance board representation (m: meter)

It was chosen the Table Tilt game from the Wii Fit Plus collection. In this game, it is possible to move the center of pressure on a tilt structure with balls on its surface. The subject is able to shift weight in order to direct the ball up to the holes (targets). Therefore, the task goal is to get the ball fall into the hole as fast as possible. When the target is achieved, the game scene is updated, increasing the level of complexity of the task.

\section{Procedures and design}

The design of this study is a case-control with repeated- measures. This way, the following steps were taken along the experimental design.

After the participants have signed the consent term, the examiners used the instruments composed by the inclusion and exclusion criteria to assess them. Three physiotherapists with a minimum of 4 year-experience in neurological rehabilitation performed the assessments.

At first moment, the task was showed to each participant followed by the instruction: "This is the task you are about to practice. It is a videogame that you use the movement of your 
body in order to play. Therefore, you need to stand on the platform, and with the movement of your trunk, you are able to control the balls into the hole. This is your objective on the task. Do it as fast as possible".

After the instruction, the researcher performed two trials in order to demonstrate the task. Afterwards, the participant performed three trials for the familiarization with the task, followed by the pre-test with five trials. The acquisition phase was composed by four trials of 30 minutes each. The blocks of practice were done in consecutive days. In the end of the last block, in same day, there was a post-test with the same characteristics of the pre-test. During and strictly only on the acquisition phase, the participant had verbal and proprioceptive feedback about his performance, when it was necessary. After that, the participants did not practice the task during 1 week. The retention test was performed, with the same characteristics of the previous tests after one week of the acquisition.

\section{Data Analysis}

The dependent variables were: (1) the game score achieved each trial (represented the level of complexity that the subject reached each trial), (2) the number of error balls, represented by the number of balls falling from the surface (number of errors for each trial), and (3) the number of correct balls (representing the number of times the participant has reached the goal task for each trial).

The normality and homogeneity of the dependent variables were verified through Shapiro Wilks and Levene tests, respectively. For the statistical analysis we considered the mean of each trial block, whereupon was considering each dependent variable a $2 \times 3$ ANOVA for repeated measures (EG and CG $\mathrm{x}$ pre-test, post-test, and retention test) was run. The identified effects were followed by the Tukey post hoc testing. The Statistica 11.0 (Stat Soft Inc., Tulsa, USA) software was used with adoption of $5 \%$ for significance level. As a complement, it was performed a correlation analysis between the game score (complexity) and the number of error balls (error) using the Pearson correlation coefficient for each group (EG and CG).

\section{RESULTS}

In the Table 1 is show the data of characterization of the CG and EG.

Table 1

Sample characterization

\begin{tabular}{lcc}
\hline $\begin{array}{l}\text { Assesment } \\
\text { Instrument }\end{array}$ & EG & CG \\
\hline Lesional topography & $10 \mathrm{RI} \mathrm{10} \mathrm{LI}$ & - \\
Gender & $12 \mathrm{M} 8 \mathrm{~W}$ & $10 \mathrm{M} 10 \mathrm{~W}$ \\
Age & $65.15( \pm 9.34)$ & $64.2( \pm 7.6)$ \\
Orpington & $3.355( \pm 0.91)$ & \\
Beck & $14.9( \pm 9.45)$ & \\
MMSE & $26.2( \pm 2.56)$ & \\
FMS & $160.8( \pm 26.13)$ & \\
BERG & $45.5( \pm 8.17)$ & \\
FRT & $20.7( \pm 7.89)$ & \\
Lesion Time & $34.15( \pm 40.57)$ & \\
\hline
\end{tabular}

Legend: Mean (standard desviation), RI: Right Injury, LI: Left Injury, M: Man, W: Woman, Orpington: Orpington Prognostic Scale, Beck: Depression Questionnaire Beck, MMSE: Mini Mental State Examination, FMS: Fugl Meyer Scale, BERG: Berg Balance Scale, FRT: Functional Reach Test $(\mathrm{cm})$, Age (years), Lesion time: (months)

Concerning the number of correct balls (goal task), a two-way ANOVA revealed effects only between pre-test and post-test $(F(1,20)=41.22$, $\left.p=.00, \eta^{2}=.81\right)$. The Tukey testing identified difference between pre and post-test $(p=.0002)$, and, pre-test and retention test $(p=.0001)$. These results demonstrate that there was no difference between CG and EG to measure correct balls and both groups increased the number of correct balls from pre to post-test and maintained it in the retention test (Figure 2).

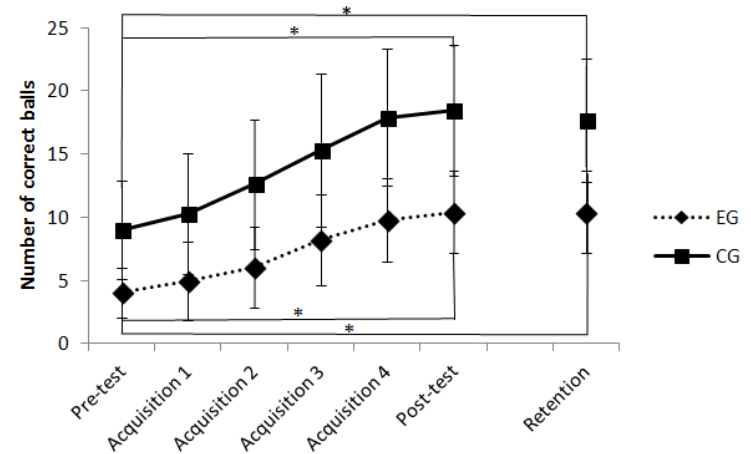

Figure 2. Mean of the average number of correct balls of the CG and EG along blocks of trials. EG: Experimental group, CG: Control group, $\left(^{*}\right)$ : significant intra-group difference. 
In relation to score (complexity level) reached in each block trial. The two-way ANOVA identified interaction effect $(F(1,20)=4.77, p=$ $\left..01, \eta^{2}=.11\right)$. The Tukey test revealed that for the intergroup analysis, the groups were not different in pre-test $(p=.33)$ but were different in the post-test $(p=.001)$ and the retention test $(p=.08)$. For intragroup analysis, the groups were different between pre- and post-test, CG ( $p$ $=.0001)$ and EG $(p=.0001)$, and, pre-test and retention test, CG $(p=.0001)$ and EG $(p=$ $.0001)$. On the other hand, the groups showed no significant difference between post-test and the retention test, CG $(p=.84)$ and EG $(p=.99)$ (Figure 3).

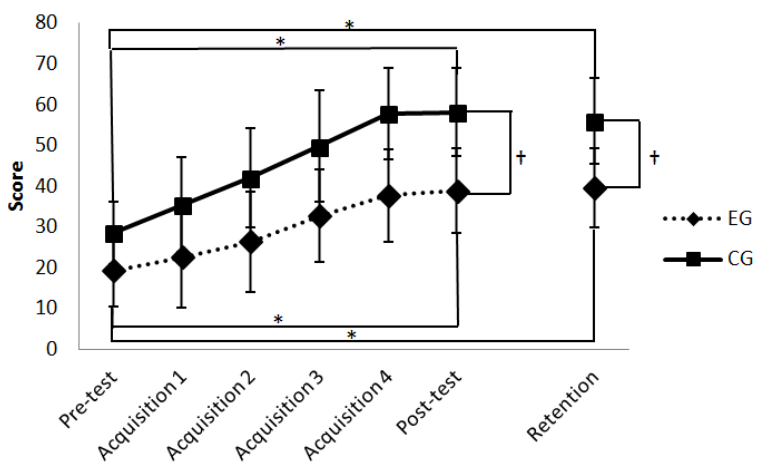

Figure 3. Mean of the mean of the score of the CG and EG along blocks of trials. EG: Experimental group, CG: Control group, $\left({ }^{*}\right)$ : significant intra-group difference $(\dagger)$ : significant intergroup difference.

These data together suggest that both groups reached higher levels of complexity in the task, and these high levels were maintained in the retention test. However, both groups showed different behaviors along the practice, since the pre-test showed the same and post-test, and retention test were different.

With respect to error balls of the CG and the EG the Anova two way test just detected significant difference intragroup $(F(1,20)=.53$, $\left.p=.00, \eta^{2}=.58\right)$ and the Tukey post hoc confirmed the significant difference between preand post-test $(p=.0001)$, and pre-test and retention test $(p=.0001)$ (Figure 4$)$.

These data suggest that both groups, CG and EG, have similar behaviors along the experiment, being that both groups increased the error number along the practice and this was maintained in the retention test and probably attributed to the increase of task complexity.

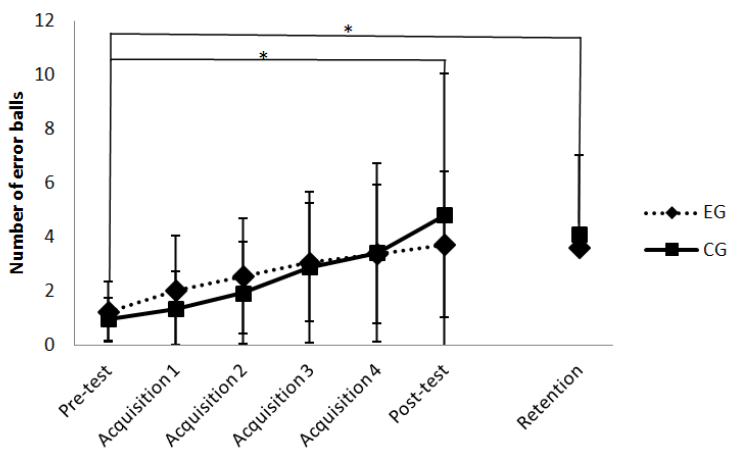

Figure 4. Mean of the Mean of the error balls CG and EG along blocks of trials. EG: Experimental group, CG: Control group, $\left({ }^{*}\right)$ : significant intra-group difference.

Finally, the Pearson correlation test showed that the EG and CG showed moderate positive correlation between the game score (level of complexity) and the number of error balls (error). The increasing of the level of complexity over the practice of blocks moderately induced increase in the number of wrong trials over the ball blocks. Being that the EG had correlation = .52 and the CG presented correlation $=.52$. Such data can explain the increase of errors along the practice because the increase of the level of complexity during the practice induced moderate increase in the number of erroneous trials along of the blocks of practice.

\section{DISCUSSION}

These results suggest that post-stroke individuals have the capacity to learn a postural control task similar to healthy individuals. Based on the correct balls measure, that expresses the task goal, the CG and EG did not differ in any phase of the experiment. Therefore, both groups improved their performance according to the practice and maintained it in the retention test, reflecting that both groups have learned the task.

Thus, the results suggest that the difference in motor learning between post-stroke and healthy individuals may be at the level of complexity of the task. This statement is based on the superiority of CG in relation to EG on the obtained complexity level. Noteworthy is the fact that both groups were not different statistically 
in the pre-test and after the acquisition there was an intergroup difference in the post-test and retention. It is clear that, with practice, the CG could perform the task at superior levels of complexity than the EG, which was maintained in the retention test.

Besides, both groups were similar to the number of erroneous balls, and increased the number of errors during the practice of task, maintaining it in the retention test. This seemed strange based on the expectation that with the practice of any motor skills, there is a decrease in error (Edwards, 2011; Schmidt \& Lee, 2011). However, the task proposed in this study showed the characteristic of increasing complexity exponentially compatible with the performance improve. This dynamic of increased complexity may be justified to moderately positive correlation between the game scores and the number of erroneous balls. These results can be attributed to the effects generated by the increase in complexity along the practice.

When comparing the findings of this study to the literature, it is possible to find the equality of motor learning capacity between post-stroke individuals and healthy subjects. These results were seem in precision manual tasks (Platz et al., 1994), in tracking tasks (Boyd \& Winstein, 2004; Vidoni \& Boyd, 2009), in serial reaction time tasks (Pohl et al., 2006) and reach and grasping tasks (Winstein et al., 1999). Thus, this study becomes unique because it is the first to investigate motor learning in a postural control task. Besides, our results corroborates to the fact that the ability to learn after a stroke is not impaired and it is similar to healthy individuals.

However, this statement should be cautious, since the multifactorial etiology and heterogeneous clinical condition of post-stroke population may affect the external validity of the data and the generalization for the stroke population. In this context, it is known that poststroke individuals with different levels of impairment may benefit from different practice schedules (Schaapsmeerders et al., 2013) or presenting distinct learning capacity (Boyd \& Winstein, 2004; Vidoni \& Boyd, 2004).

The study of Pohl, Mcdowd, Filion, Richards, and Stiers (2006) indicates that individuals with mild and moderate impairment are similar to the healthy individuals in learning tasks; however, the individuals with severe impairment are different from the healthy subjects. Thus, we can assume that the mild/moderate impairment characteristics of our sample can justify the similar results in motor learning between EG and CG.

Moreover, the absence of a learning test such as the retention test may provide a false detection of motor learning difference between post-stroke subjects and healthy subjects. In fact, the studies of Boyd, Quaney, Pohl, and Winstein (2007), Iofee, Chernikova, Umarova, Katsuba, and Kulikov (2010), Pool and Winstein (1999) and Ustinova, Chernikova, Iofee, and Silva (2001) showed differences between post-stroke and control subjects. However, they have analyzed the acquisition phase with no learning test (retention and / or transfer).

This study is relevant and contributes to the body of knowledge in the literature, because investigates the comparison of motor learning (including a retention test) of a postural control task between post-stroke individuals and healthy individuals. Besides, the retention test after a week with no practice allows inferring about the long-term-retention, which is measured only when the deleterious or increase effects of the performance variables are forgotten (Fischman, Cristina, \& Vercruysen, 1982).

This principle of offering the time necessary to the performance variables dissipate is essential for motor learning experiments. As an example may be mentioned the study by Vidony and Boyd (2009), in which it was detected significant differences between the motor learning of poststroke individuals and healthy subjects.

In principle may seem unexpected that poststroke individuals have similar motor learning that in healthy individuals. This is because this population has perceptual-motor and cognitive deficits (Carr \& Shepherd, 2003; Shumway-Cook \& Woollacott, 2010) which might result in a poor performance compared to healthy subjects. However, the motor performance improvement of these individuals do not necessarily requires improvement in motor structures. It may be that the performance improvement is derived from a 
compensatory mechanism that is learned and retained (Levin, Kleim, \& Wolf, 2009).

Additionally, the results of this study suggest that the effects of complexity differ post-stroke individuals from healthy subjects. Complexity is an element that has been well investigated in healthy subjects and has a strong influence on performance (Wulf \& Shea, 2002). Apparently, the results of this study also suggest that the complexity is an element that directly influences the performance of post-stroke individuals in postural control tasks and, until the present moment, there have been no studies that investigated this element. Our study did not target to investigate the complexity itself, but it became clear that this is an important variable to be investigated in the future in this population.

Finally, the present study has some methodological limitations: 1 - The task was conducted in a commercial video game system, and did not allow the researcher to modify the practice parameters during the acquisition. 2 The practice time on each trial was determined by the degree of complexity that the participant has achieved at the end of the task. Therefore, those who could overcome the complexity levels proposed by the game remained more time performing the task on each trial. To solve this problem, the practice was controlled by the time of performance. 3 - It was not performed the functional magnetic resonance imaging of the subjects, as done by Boyd and Winstein (2004) and Boyd et al. (2007), which does not allow the analysis of the injured brain volume for each subject. 4 - There was no kinematic evaluation of patients while performing the task, preventing consideration of the performance improvement was originated from compensatory mechanisms, as was done by Cirstea, Mitnitski, Feldman, and Levin (2003) and Platz et al. (1994).

\section{CONCLUSION}

It is concluded that post-stroke individuals have similar learning capacity of a postural control task as healthy individuals. However, the capacity to learn a postural control task in higher levels of complexity makes post-stroke individuals differ negatively of the healthy individuals.

\section{Acknowledgments:}

Nothing to declare

\section{Conflict of interest:}

Nothing to declare

\section{Funding}

This research was performed with support from CAPES, organization of the Brazilian government dedicated for developing human recourses.

\section{REFERÊNCIAS}

Roger, V. L., Go, A. S., Lloyd-Jones, D. M., Benjamin, E. J., Berry, J. D., Borden, W. B., ... American Heart Association Statistics Committee and Stroke Statistics Subcommittee. (2012). Heart disease and stroke statistics--2012 update: a report from the American Heart Association. Circulation, 125(1), e2-e220. https://doi.org/10.1161/CIR.0b013e31823ac04 6

Batchelor, F.A., Mackintosh, S.F., Said, C.M., \& Hill, K.D (2012). Falls after stroke. International Journal of Stroke, 7(6), 482-490. doi: 10.1111/j.1747-4949.2012.00796.

Beck, A.T. (1967). Depression: Causes and treatment. Philadelphia: University of Pennsylvania Press.

Berg, K. (1993). Measuring balance in elderly: validation of an instrument. Montreal: Mcgill University.

Bertolucci, P.H.F., Brucki, S.M.D., Campacci, S.R., \& Juliano, I. (1994). O mini-exame do estado mental em uma populaçäo geral: impacto da escolaridade. Arquivos de Neuropsiquiatria, 52(1), 1-7. doi: http://dx.doi.org/10.1590/S0004282X1994000100001

Boyd, L. A., Quaney, B. M., Pohl, P. S., \& Winstein, C. J. (2007). Learning implicitly: effects of task and severity after stroke. Neurorehabilitation and Neural Repair, 21(5), 444-454. https://doi.org/10.1177/1545968307300438

Boyd, L. A., Vidoni, E. D., \& Wessel, B. D. (2010). Motor learning after stroke: is skill acquisition a prerequisite for contralesional neuroplastic change? Neuroscience Letters, 482(1), 21-25. https://doi.org/10.1016/j.neulet.2010.06.082

Boyd, L. A., \& Winstein, C. J. (2004). Cerebellar stroke impairs temporal but not spatial accuracy during implicit motor learning. Neurorehabilitation and Neural Repair, 18(3), 134-143. https://doi.org/10.1177/0888439004269072

Carr, J., \& Shepherd, R. (2003) Stroke Rehabilitation: Guidelines for Exercise and Training to Optimize Motor Skills. Edinburgh: Elsevier Science Limited. 
Cirstea, M. C., Mitnitski, A. B., Feldman, A. G., \& Levin, M. F. (2003). Interjoint coordination dynamics during reaching in stroke. Experimental Brain Research, 151(3), 289-300. https://doi.org/10.1007/s00221-003-1438-0

Duncan, P. W., Weiner, D. K., Chandler, J., \& Studenski, S. (1990). Functional reach: a new clinical measure of balance. Journal of Gerontology, 45(6), M192-197.

Edwards, W.H. (2011). Motor Learning and Control: From Theory to Practice. Belmont: Wadsworth.

Fischman, M. G., Christina, R. W., \& Vercruyssen, M. J. (1981). Retention and Transfer of Motor Skills: A Review for the Practitioner. Quest, 33(2), 181194.

https://doi.org/10.1080/00336297.1981.10483 753

Fugl-Meyer, A. R., Jääskö, L., Leyman, I., Olsson, S., \& Steglind, S. (1975). The post-stroke hemiplegic patient. 1. a method for evaluation of physical performance. Scandinavian Journal of Rehabilitation Medicine, 7(1), 13-31.

Horak, F.B., Macpherson, J.M. (1996). Postural orientation and equilibrium. In Rowell, L.B., \& Sherpherd, J.T. (Eds.), Handbook of physiology: a critical, comprehensive presentation of physiological knowledge and concepts (pp. 255292). New York: Oxford American Physiological Society.

Ioffe, M. E., Chernikova, L. A., Umarova, R. M., Katsuba, N. A., \& Kulikov, M. A. (2010). Learning postural tasks in hemiparetic patients with lesions of left versus right hemisphere. Experimental Brain Research, 201(4), 753-761. https://doi.org/10.1007/s00221-009-2091-z

Kitago, T., \& Krakauer, J.W. (2013). Motor learning principles for neurorehabilitation. In Barnes, M.P., \& Good, D.C. (Eds.), Handbook of Clinical Neurology and Neurological Rehabilitation (pp. 93-103). New York: Elsevier.

Krakauer, J. W. (2006). Motor learning: its relevance to stroke recovery and neurorehabilitation. Current Opinion in Neurology, 19(1), 84-90.

Lai, S. M., Duncan, P. W., \& Keighley, J. (1998). Prediction of functional outcome after stroke: comparison of the Orpington Prognostic Scale and the NIH Stroke Scale. Stroke; a Journal of Cerebral Circulation, 29(9), 1838-1842.

Langhorne, P., Bernhardt, J., \& Kwakkel, G. (2011). Stroke rehabilitation. The Lancet, 377(9778), 1693-1702. https://doi.org/10.1016/S01406736(11)60325-5

Levin, M. F., Kleim, J. A., \& Wolf, S. L. (2009). What do motor «recovery" and "compensation" mean in patients following stroke? Neurorehabilitation and Neural Repair, 23(4), 313-319. https://doi.org/10.1177/1545968308328727
Magill, R.A. (2000). Aprendizagem Motora: conceitos e aplicações. São Paulo: Edgard Blücher.

Oliveira, C. B., Medeiros, I. R. T., Frota, N. A. F., Greters, M. E., \& Conforto, A. B. (2008). Balance control in hemiparetic stroke patients: main tools for evaluation. Journal of Rehabilitation Research and Development, 45(8), 1215-1226.

Platz, T., Denzler, P., Kaden, B., \& Mauritz, K. H. (1994). Motor learning after recovery from hemiparesis. Neuropsychologia, 32(10), 12091223.

Pohl, P. S., McDowd, J. M., Filion, D., Richards, L. G., \& Stiers, W. (2006). Implicit learning of a motor skill after mild and moderate stroke. Clinical Rehabilitation, 20(3), 246-253.

Pohl, P. S., \& Winstein, C. J. (1999). Practice effects on the less-affected upper extremity after stroke. Archives of Physical Medicine and Rehabilitation, 80(6), 668-675.

Schaapsmeerders, P., Maaijwee, N. A. M., van Dijk, E. J., Rutten-Jacobs, L. C. A., Arntz, R. M., Schoonderwaldt, H. C., ... de Leeuw, F.-E. (2013). Long-term cognitive impairment after first-ever ischemic stroke in young adults. Stroke; a Journal of Cerebral Circulation, 44(6), 16211628.

https://doi.org/10.1161/STROKEAHA.111.000 792

Schmidt, R.A., \& Lee, T.D. (2011). Motor control and learning: a behavioral emphasis ( $5^{\text {th }}$ ed.). Champaign: Human Kinetics.

Schmidt, R.A., \& Wrisberg, C.A. (2008). Aprendizagem e Performance Motora. Porto Alegre: Editora Artmed.

Shumway-Cook, A., \& Woollacott, M.H. (2010). Controle Motor: Teoria e Aplicações Práticas. Barueri: Manole.

Ustinova, K. I., Chernikova, L. A., Ioffe, M. E., \& Sliva, S. S. (2001). Impairment of learning the voluntary control of posture in patients with cortical lesions of different locations: the cortical mechanisms of pose regulation. Neuroscience and Behavioral Physiology, 31(3), 259-267.

Vidoni, E. D., \& Boyd, L. A. (2009). Preserved motor learning after stroke is related to the degree of proprioceptive deficit. Behavioral and Brain Functions: $\quad B B F, \quad 5, \quad 36$. https://doi.org/10.1186/1744-9081-5-36

Wilson, B.A., Cockburn, J., \& Halligan, P.W. (1987). Behavioural Inattention Test. Titchfield, Hants, England: Thames Valley Test Company Ltd.

Winstein, C. J., Merians, A. S., \& Sullivan, K. J. (1999). Motor learning after unilateral brain damage. Neuropsychologia, 37(8), 975-987.

Wulf, G., \& Shea, C. H. (2002). Principles derived from the study of simple skills do not generalize to complex skill learning. Psychonomic Bulletin \& Review, 9(2), 185-211. 